\title{
RELAÇÃO DOS MORADORES DOS BAIRROS PERIFÉRICOS COM O MÓDULO MANDHUY - PARQUE MUNICIPAL CINTURÃO VERDE, CIANORTE-PR
}

\author{
Nadir Leandro de Souza ${ }^{12}$
}

\section{RESUMO}

Este estudo teve como objetivo verificar a relação da população lindeira com o Módulo Mandhuy, parte do Parque Municipal Cinturão Verde em Cianorte-PR. Para tanto, foram analisadas respostas de 70 moradores, dos bairros Zona 3, Zona 7 e do Conjunto Moradias Marselha, imediatamente limítrofes do Módulo Mandhuy, os quais responderam a questões estruturadas do tipo aberta, tendo a opção do respondente expressar opiniões, sendo então possível avaliar a interação da comunidade lindeira com a área e com os elementos naturais constituintes do mesmo, além de verificar os possíveis conflitos de interesse, entre as reais necessidades dos moradores por espaços de lazer e proteção ambiental.

Palavras-chave: Unidade de Conservação; Áreas Verdes Urbanas; Relação Sociedade-natureza.

\section{RELATION OF THE RESIDENTS OF THE OUTLYING DISTRICTS WITH MODULE MADHUY - MUNICIPAL PARK GREEN BELT, CIANORTE - PR.}

\section{ABSTRACT}

This study aimed to verify the relation between the population bordering and the Mandhuy Module, part of Cinturão Verde City Park, Cianorte-PR. For this purpose, there were analyzed responses of seventy residents of the neighborhoods Zone 3, Zone 7 and the Marseille set of houses, limitrophe to the Mandhuy Module, which responded to open questions, in which the respondent could express opinions. Thus enabling the evaluation of the interaction of neighboring communities to the area and with the natural elements of the its constituents, and to identify possible conflicts of interest between the real needs of residents for leisure and the environmental protection.

Keywords: Conservation Units; Urban Green Areas; Society-nature Relation

\footnotetext{
${ }^{1}$ Mestre e Doutoranda em Geografia / PGE - Universidade Estadual de Maringá - PR nadirleandro@gmail.com Cianorte/PR

2 (recebido em 28.07.2011 e aceito para publicação em 15.06.2012)
} 


\section{INTRODUÇÃO}

No Brasil a história das unidades de conservação se reporta ao período colonial. Como marco inicial das Unidades de Conservação no país, se aceita amplamente entre os pesquisadores a criação do Parque Nacional de Itatiaia. Entretanto, Paz et al (2006) argumentam que o Itatiaia é a primeira Unidade de Conservação em esfera federal, já que em 1886, em São Paulo, foi criado o Parque Estadual da Cidade.

As áreas naturais protegidas, em diferentes categorias, denominadas Unidades de Conservação (UC), são regidas e definidas pelo Sistema Nacional de Unidades de Conservação (SNUC), criado pela Lei n ${ }^{\circ} 9.985$, de 18 de julho de 2000 (BRASIL, 2000). Na categoria Unidades de Conservação de Proteção Integral têm-se os Parques Nacionais, Estaduais e Municipais, com finalidades diversas, dentre as quais pode-se destacar a preservação dos recursos naturais e opção de lazer para as populações e consequente melhoria em sua qualidade de vida.

As unidades de conservação, quando presentes nas cidades, compõem as áreas verdes urbanas, e que de acordo com Ferreira (2005, p.25) tem por objetivo “[...] a conservação dos recursos naturais, em geral de remanescente de vegetação em área que estão sob pressão dos impactos gerados por diversos fatores decorrentes da urbanização”. Também podem ser denominadas florestas urbanas, segundo Paiva e Gonçalves (2002, p.20) são “[...] áreas verdes de preservação e/ou conservação [...] cuja finalidade é a conservação do sitio ou a manutenção da biodiversidade”.

As dificuldades de manutenção dessas áreas em espaço urbano são enormes a começar pela execução dos procedimentos relacionados à proteção, fiscalização e interação com as comunidades de entorno. Necessitando de estudos que busquem a integração da área protegida com as áreas urbanizadas, evitando-se com isso seu uso irregular. Mas apesar disso, constituem-se em importantes elementos, ampliando a arborização urbana, produzindo efeitos positivos ao ambiente, melhorando a qualidade de vida na cidade e contribuindo para a preservação dos parcos recursos vegetais presentes em algumas cidades.

Mazzei et al (2007) realizaram estudos com o Parque Estadual da Serra da Cantareira, em São Paulo, o Parque do Sabiá e o Parque Siqueirolli em Uberlândia, Minas Gerais, onde propuseram-se fazer uma comparação entre essas unidades, observando os limites de visitação e também considerando o tamanho das cidades onde estas unidades estão inseridas. A visitação nas referidas áreas é permitida e seus objetivos é o turismo ecológico, muito embora, destacam que: “em algumas áreas dos parques a visitação também é proibida, pois o principal objetivo é a conservação e recuperação”. Mazzei et al (2007, p.36)

Em UCs de grande porte os problemas relacionam-se à fiscalização das atividades econômicas no seu interior e entorno, enquanto que os problemas das UCs presentes em áreas urbanas, os problemas estão diretamente relacionados a integração destas com o sistema urbano.

Como estratégia de investigação, nesta pesquisa cientifica, que tem como tema uma Unidade de Conservação em espaço urbano, o Módulo Mandhuy, parte constituinte do Parque Municipal Cinturão Verde de Cianorte, será o estudo de caso. Para YIN (2001) essa forma de investigação, é adequada, principalmente para investigar os fenômenos muito abrangentes que dificultam o tratamento metodológico, a partir da relação sociedade-natureza de forma integradora proposta pela Geografia Socioambiental, sendo o foco principal da investigação a relação da comunidade de entorno do Módulo Mandhuy e as finalidades de preservação para quais a área se destina. 


\section{MATERIAIS E MÉTODOS}

\subsection{Caracterização da Área de Estudo}

O processo de ocupação do espaço brasileiro, em algumas regiões, resultou na quase total supressão da cobertura vegetal original. O Norte e Noroeste do Estado do Paraná constituem-se em exemplos típicos dessa questão, pois foram objetos de colonização, realizados pela Companhia Melhoramentos Norte do Paraná (CMNP), quando a vegetação foi rapidamente retirada para dar lugar às atividades agropecuárias. Esse processo de ocupação foi responsável pela drástica redução florestal, sendo que hoje os remanescentes não ultrapassam os 2,5\% de cobertura vegetal nativa (IAP, 2000).

A partir dos anos de 1980, por intermédio do poder público, deu-se início a algumas tentativas para se preservar esses fragmentos vegetais, que consistem em uma paisagem natural presente em meio à área urbana de Cianorte, muito embora altamente degradada e que, com a preservação, a população passaria a ter opção para diferentes atividades de lazer, além de se constituir em um espaço propício ao desenvolvimento da educação ambiental.

Os remanescentes florestais não se distribuem de maneira homogênea por sobre o território do município. Concentram-se em pequenas ilhas de matas geralmente já bem exploradas, e próximas ao perímetro urbano. A vegetação ainda presente no perímetro urbano de Cianorte acompanha linearmente os cursos d'água localizados na malha urbana. Compreendendo uma área de um pouco mais de 300 hectares, compondo o que se acostumou a denominar "Cinturão Verde de Cianorte", onde se incluem os 20,97 hectares da área do primeiro módulo criado, o Módulo Manduhy, objeto de nosso estudo, hoje com área superior a 88 hectares.

De acordo com Lei Municipal $n^{0} 1.534$, que criou o Parque Municipal do Cinturão Verde - Módulo Mandhuy, em 1993, com área total de 209.763,47 m² a partir do ano 2000, a área do Mandhuy ultrapassou 88 hectares, faz parte do Parque Cinturão Verde de Cianorte (PCVC) formado em 2000, que é constituído por vários módulos que representam fragmentos vegetais separados um do outro pela urbanização. (Figura 1).

Os módulos constituintes do PCVC se encontram distantes uns dos outros, além dos módulos Fantasminha, Uruçora e das Perobas, onde os módulos Fantasminha e Uruçora são conectados e o Módulo das Perobas separase dos demais por uma Rodovia, além de ser atravessado por uma estrada vicinal, assim como o Módulo Fantasminha que é cortado por uma estrada de ligação para os novos loteamentos que estão se configurando na sua porção oeste do plano original da cidade.

De acordo com lei que institui o SNUC, o Parque Cinturão Verde de Cianorte constitui uma Unidade de Conservação Integral de uso restrito, com a finalidade de preservação, educação ambiental e realização de pesquisas científicas.

Residem no entorno do Mandhuy, segundo dados do Instituto Brasileiro de Geografia e Estatística (2000), 15.867 pessoas, considerando que parte desse total (662), corresponde à população da zona rural, tendo em vista que a porção sul do Mandhuy limita-se à Rodovia 323. Com isso considera-se a população residente, nessas imediações, como componente do total dos moradores do entorno dessa área.

\subsection{Aquisição dos dados}

Para investigar a relação dos moradores nos bairros periféricos com o Módulo Mandhuy (Figura 2) foi usado um questionário com 8 questões com duas alternativas (Sim e Não) cada, e com a possibilidade do entrevistado justificar sua posição em relação ao assunto questionado, com exceção da primeira que buscou saber o tempo de residência do morador no entorno do Mandhuy.

O questionário foi aplicado a 43 moradores da zona 3, 7 moradores da zona 7 e 20 moradores do Conjunto Moradias Marselha, totalizando 70 moradores. (Quadro $1)$.

A investigação com os moradores do entorno imediato do Módulo Mandhuy, parte do Parque municipal Cinturão RELAÇÃO DOS MORADORES DOS... 
Verde, foi norteada em experiências de estudos anteriores realizados em outros parques do Brasil, sendo relevantes as pesquisas de Ferreira (2005), Ballarotti (2005), Biondi e Mórmul (2004).

Figura 1. Mapa do Parque Municipal Cinturão Verde de Cianorte - Módulos identificados

Figure 1. Map of the Green Belt Municipal Park from Cianorte - Identified modules

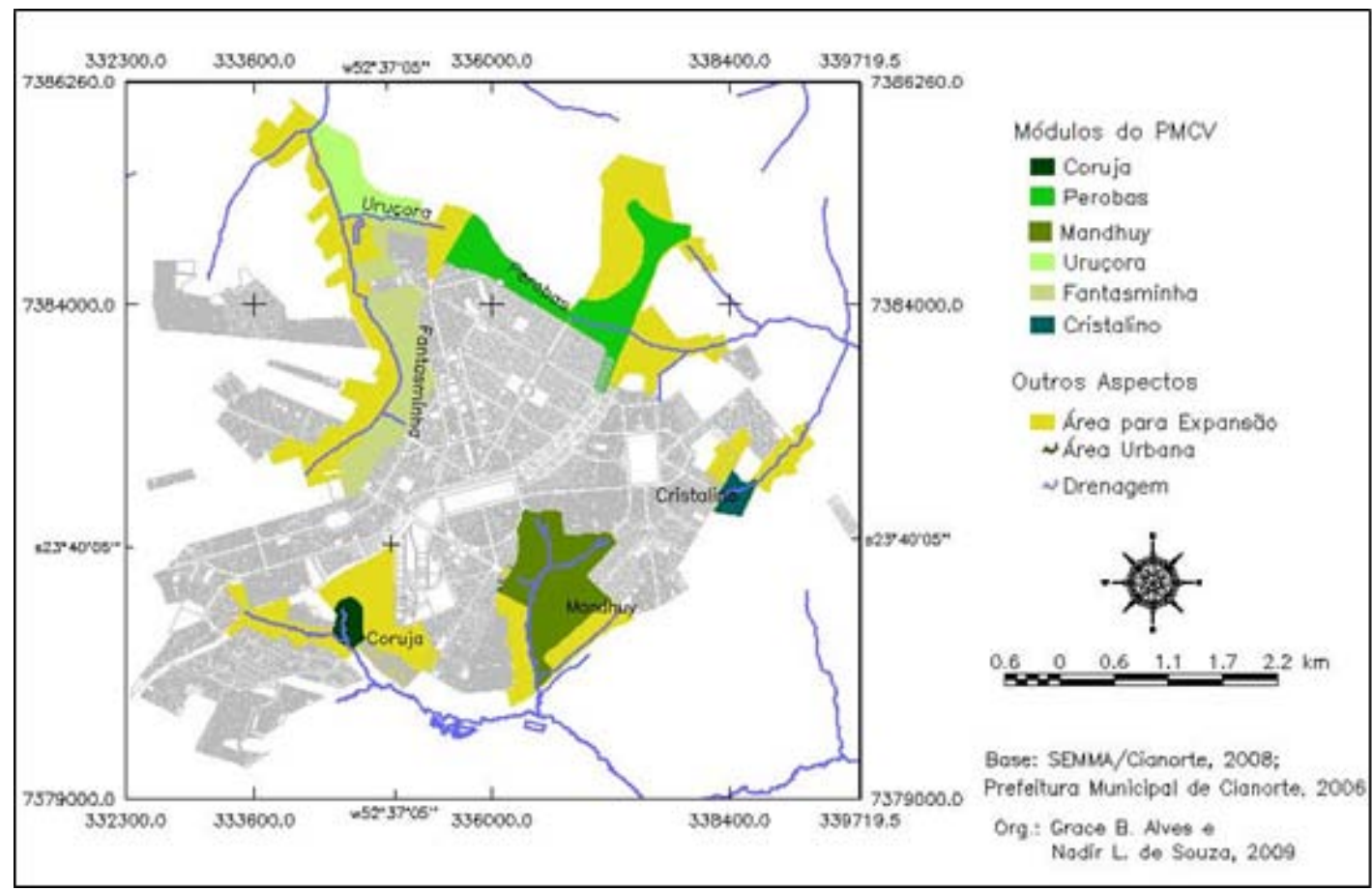

Figura 2. Mapa do Módulo Mandhuy - Bairros do entorno

Figure 2. Map of Mandhuy Module - Surrounding neighborhoods

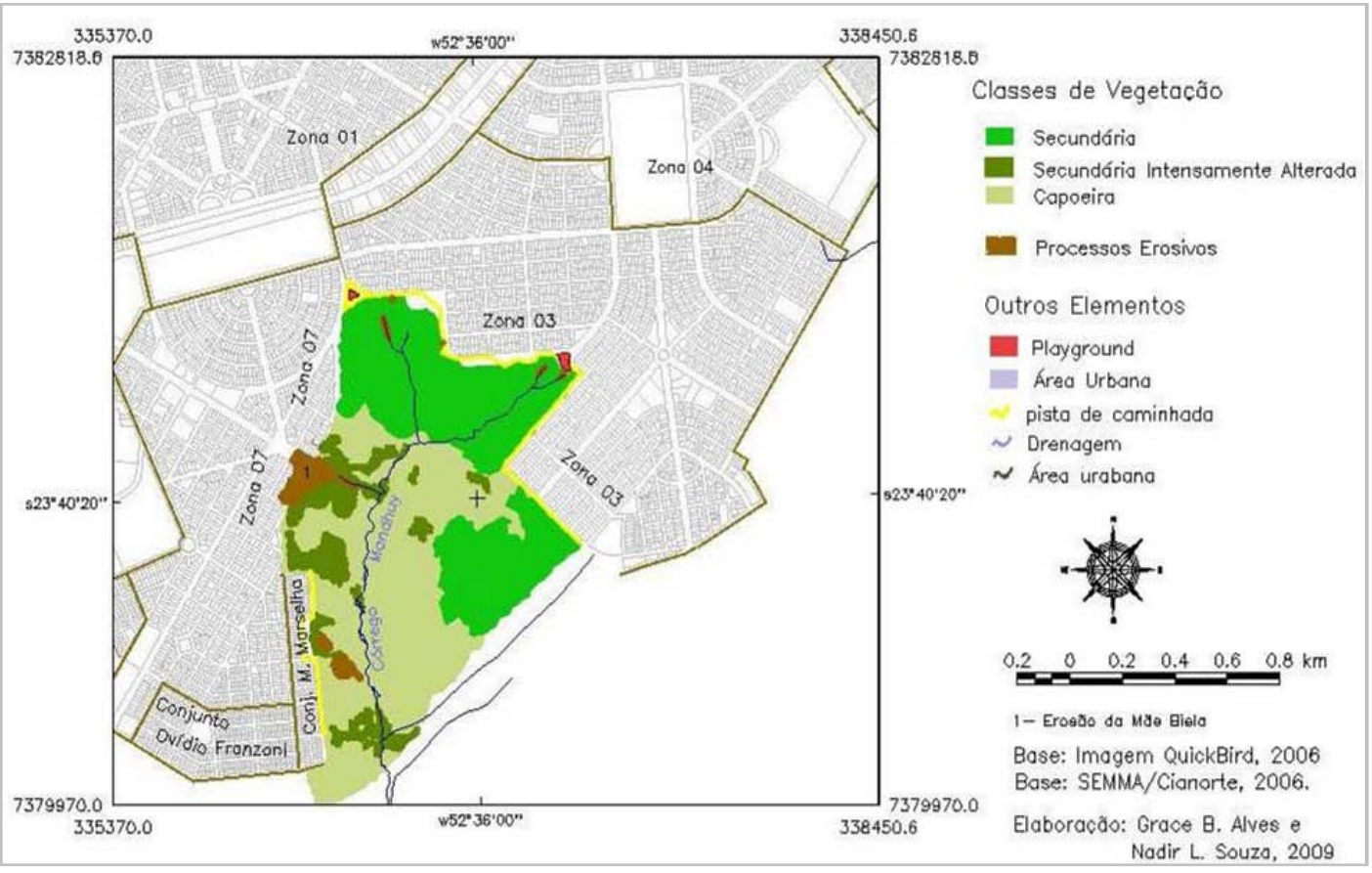


Para a consulta junto à comunidade foi estabelecida a seguinte metodologia: como o perímetro do Mandhuy, com residências é da ordem de $4.640 \mathrm{~m}$, optou-se pela seleção alternada das residências. Como as entrevistas foram realizadas em dias úteis, os moradores de diversas residências não foram encontrados. Mesmo assim foi possível entrevistar 70 moradores.

Para a seleção dos bairros adjacentes à área de estudo, utilizou-se a base cartográfica urbana digital da cidade de
Cianorte, disponibilizadas pela Prefeitura Municipal de Cianorte, Departamento de Obras, organizado em bairros, quadras, ruas e avenidas, espaços livres, praças e parques, em AutoCAD.

As respostas dos moradores foram analisadas mediante o enfoque da Geografia Socioambiental procurando considerar de forma integrada as questões do meio físico e os elementos culturais que norteiam as ações dos moradores imprimidas à área da unidade de conservação.

Quadro 1. Questionário aplicado aos moradores do entorno imediato do Módulo Mandhuy

Board 1. Questionnaire applied to residents of the immediate surroundings Module Mandhuy

1) Há quanto tempo você mora no entorno do Módulo Mandhuy?

( ) Até 1 ano ( ) 1 ano a 3 anos ( ) 3 anos a 5 anos ( ) Mais de 5 anos

2) Você gosta de morar perto do Módulo Mandhuy?

( ) Sim. Porque?

( ) Não. Porque?

3) A existência do Parque Mandhuy causa-lhe insegurança, algum incômodo?

( ) Sim. Porque?

( ) Não. Porque?

4) Você se mudaria para outra rua ou bairro mais distante do Módulo Mandhuy?

( ) Sim. Porque?

( ) Não. Porque?

5) Você sabe para que serve essa área?

( ) Sim

( ) Não

6) Essa área lhe traz algum beneficio?

( ) Sim. Qual (is)?

( ) Não.

7) Você saberia informar quem joga lixo na área do Módulo Mandhuy?

( ) Sim. Quem?

( ) Não.

8) Você faz alguma coisa para cuidar do Módulo Mandhuy?

( ) Sim. O quê?

( ) Não. Porque?

A análise de uma questão de âmbito ambiental, sob o enfoque da Geografia Socioambiental, deverá trazer em seu âmago a integração do meio ambiental e a sociedade ali representada. Sob esse aspecto, Mendonça (2004, p.134) ressalta que um estudo em conformidade com essa concepção,

[...] deve emanar de problemáticas em que situações conflituosas, decorrentes da interação entre a sociedade e a natureza, explicitem degradação de uma ou de ambas. A diversidade das problemáticas é que vai demandar um enfoque mais centrado na dimensão natural ou mais na dimensão social, atentando sempre para o fato de que a meta principal de tais estudos $e$ ações vai na direção da busca de soluções do problema, e que este deverá ser abordado a partir da interação entre estas duas componentes da realidade.

Na visão de Souza e Suertegaray (2007, p.13):

[...] pensar o ambiente em geografia e considerar a relação natureza/ sociedade, uma conjunção complexa e conflituosa que resulta do longo processo de socialização da natureza pelo homem. Processo este que, ao mesmo tempo em que transforma a natureza, transforma, também, a natureza humana.

Gonçalves (2005, p. 74) afirma com muita lucidez que:

É preciso romper com o pensamento simplificador $e$ excludente e afirmar a complexidade. Afinal, alguns só querem falar da rosa. Outros só destacam o espinho. É 
necessário que se elabore a visão que comporta tanto a rosa, quanto o espinho: a visão da roseira.

Souza e Suertegaray (2007, p.13) compreendem que a análise integrada das questões sociais e ambientais significa,

[...] resgatar a união entre Natureza e Sociedade, união esta que nos foi embrionária, e que representa um dos maiores diferenciais inerentes à história dessa Ciência, quando comparada a outras, significa superar a dicotomia criada ao longo do seu processo histórico para que assim possamos dar respostas mais efetivas aos desafios científicos que nos são propostos.

A aplicabilidade dessa abordagem demanda, segundo Mendonça (2004, p. 136),

[...] tanto a aplicação de métodos já experimentados no campo de várias ciências particulares, quanto à formulação de novos. Mas esta característica não é uma particularidade somente da abordagem ambiental, ela reflete a identidade própria da geografia em muitas de suas experiências.

Neste contexto, na perspectiva de análise da Geografia Socioambiental, será possível investigar a relação conflituosa da comunidade residente próxima à área de estudo. No entanto, não se deve desconsiderar o fato de que uma área protegida, localizada em espaço urbano, será intensamente influenciada pela comunidade presente em seu entorno, e também irá condicionar muitas das ações das comunidades vizinhas que, em sua maioria, não compreendem o porquê da existência de uma Unidade de Conservação dentro de uma cidade.

\section{RESULTADOS E DISCUSSÃO}

De acordo com os dados obtidos junto aos moradores para a Questão 1, a maioria (67\%) dos entrevistados reside há mais de 5 anos nesse local. Entretanto, é mister frisar que a Zona 3 e a Zona 7 são bairros bem antigos. Foram loteados já no Plano Piloto de Cianorte, pela CMNP, no inicio da Colonização do Município. Portanto, tendo hoje mais de 50 anos (Cianorte completa 59 anos em 2012), já que o Conjunto Moradia Marselha foi loteado em março de 2000, sendo que as primeiras residências foram construídas somente a partir de 2001. Assim, nenhum dos entrevistados desse bairro reside há mais de dez anos no entorno do Mandhuy (Tabela 1).

De acordo com os dados referentes aos moradores da Zona 3 e Zona 7, nota-se que estes já residem próximo ao Mandhuy há muitos anos. Alguns fizeram questão de informar que estão ali há mais de 30 anos e acompanharam todo o processo de transformação dessa paisagem.

Para a questão 2 (Tabela 2), 95\% dos entrevistados afirmaram que gostam de morar perto desse espaço e as razões para essa escolha refere-se principalmente à presença da "mata”, associando o Mandhuy a tranquilidade, sossego e melhor qualidade ambiental. Algumas respostas, dadas pelos moradores, destacam efeitos positivos que o Mandhuy promove no ambiente onde residem. Afirmaram que a existência dessa área vegetada contribui para tornar o ambiente melhor.

Dentre as principais razões apontadas pelos moradores como elementos que contribuem favoravelmente para que esses residam próximos ao Módulo Mandhuy, destacamse os efeitos positivos demonstrados na Figura 3.

Para os poucos moradores que se manifestaram contrários à maioria, a mata representa um espaço de medo, enfocando a presença de desocupados e usuários de drogas que circulam diariamente pela área do parque.

Para a Questão 3 - A existência do Módulo Mandhuy causa-lhe insegurança ou algum incômodo? - os moradores do entorno se dividiram em dois grupos bem semelhantes (Tabela 3), 51\% deles responderam que a existência do Mandhuy causa-lhe algum tipo de insegurança ou incômodo, enquanto que $49 \%$ afirmaram o contrário. 
Tabela 1. Tempo de residência dos moradores do entorno do Módulo Mandhuy

Table 1. Residence time of the residents surrounding from module Mandhuy

\begin{tabular}{lcccc}
\hline \hline Tempo de residência & Zona 03 & Zona 07 & $\begin{array}{c}\text { Conj. Moradias } \\
\text { Marselha }\end{array}$ & $\%$ \\
\hline Até 1 ano & 5 & 1 & 7 & 18,6 \\
De 1 a 3 anos & 1 & - & 3 & 5,7 \\
De 3 a 5 anos & 3 & - & 3 & 8,6 \\
Mais 5 anos & 34 & 6 & 7 & 67,1 \\
& & & $\mathbf{2 0}$ & $\mathbf{1 0 0 , 0}$ \\
\hline Total & $\mathbf{4 3}$ & $\mathbf{7}$ & & \\
\hline \hline
\end{tabular}

Tabela 2. Manifestação dos moradores do entorno do Módulo Mandhuy quanto à satisfação do local de moradia

Table 2. Manifestation of the surrounding residents from Mandhuy Module as for as the satisfaction of the local living

\begin{tabular}{l|c|c|c|c}
\hline \multirow{2}{*}{ Bairro } & \multicolumn{2}{|c|}{ Sim } & \multicolumn{2}{c}{ Não } \\
\cline { 2 - 5 } & $\mathrm{N}^{\circ}$ absoluto & $\%$ & $\mathrm{~N}^{\circ}$ absoluto & \% \\
\hline Zona 03 & 41 & 95 & 2 & - \\
Zona 07 & 7 & 100 & 1 & 5 \\
Conj. M. Marselha & 19 & 95 & $\mathbf{0 3}$ & $\mathbf{5}$ \\
\hline Total & $\mathbf{6 7}$ & $\mathbf{9 5}$ & & 5 \\
\hline \hline
\end{tabular}

Figura 3. Razões que contribuem para os entrevistados residirem perto do Módulo Mandhuy

Figure 3. Reasons that contribute to the interviewed people live close to the Mandhuy Module

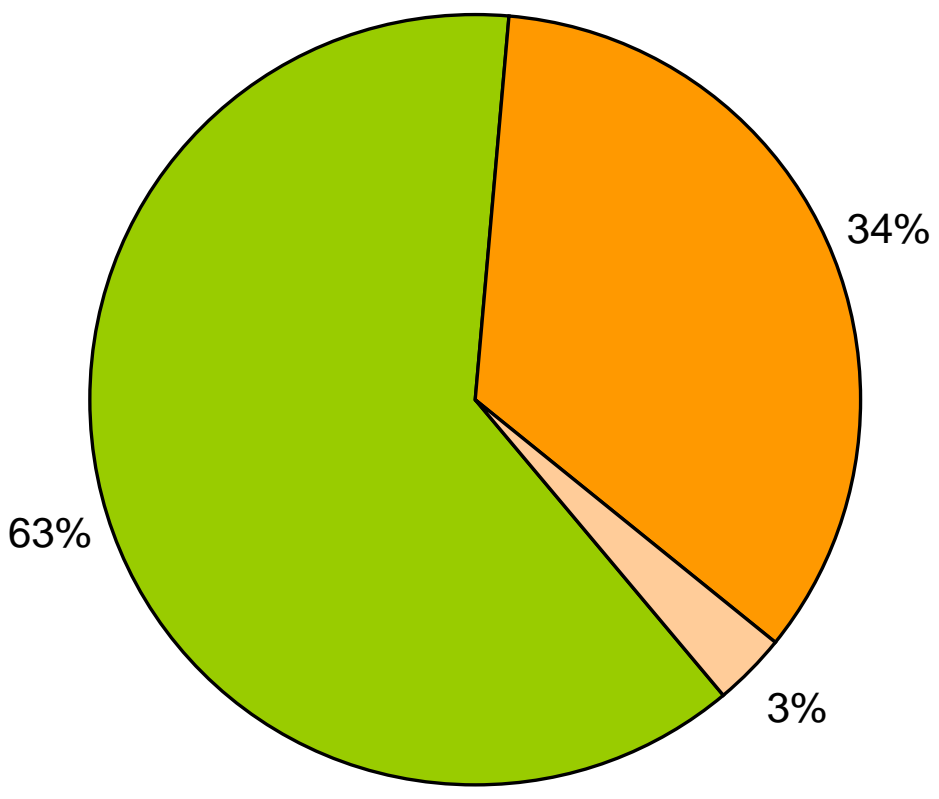

口Efeitos positivos

口Presença da natureza

口Outros 
Tabela 3. Existência do Módulo Mandhuy e a questão da insegurança ou incômodo

Table 3. The existence of the Mandhuy Module and the issue of insecurity or discomfort

\begin{tabular}{lc|c|c|c}
\hline \hline Bairro & \multicolumn{2}{c}{ Sim } & \multicolumn{2}{c}{ Não } \\
\cline { 2 - 5 } & $\mathrm{N}^{\mathrm{o}}$ absoluto & $\%$ & $\mathrm{~N}^{\mathrm{o}}$ absoluto & $\%$ \\
\hline Zona 03 & 22 & 51 & 21 & 49 \\
Zona 07 & 04 & 57 & 03 & 10 \\
Conj. M. Marselha & 10 & 50 & 10 & $\mathbf{4 9}$ \\
\hline Total & $\mathbf{3 6}$ & $\mathbf{5 1}$ & $\mathbf{3 4}$ & \\
\hline \hline
\end{tabular}

O grupo de moradores que associa o Módulo Mandhuy à insegurança ou incômodo, apresentaram justificativas semelhantes. Manifestou preocupações relacionadas a segurança do espaço.

Dos entrevistados 56\% apontaram o Módulo Mandhuy como sinônimo de insegurança, e 22\% identificaram que a existência dessa área atrai pessoas estranhas que contribui para a sensação de insegurança. Este resultado é corroborado por Seraphim (2010) em estudo realizado em parques de Curitiba, PR, onde aponta que a falta de segurança nessas áreas sugere a necessidade de maior investimento neste quesito. Número igual de entrevistados, identifica os componentes bióticos (fauna e flora) da área como as causas para sua insegurança e incômodo (Figura 4).

Figura 4. Principais fatores de insegurança e incômodo relacionado ao Mandhuy

Figure 4. Main factors of insecurity and discomfort related to Mandhuy

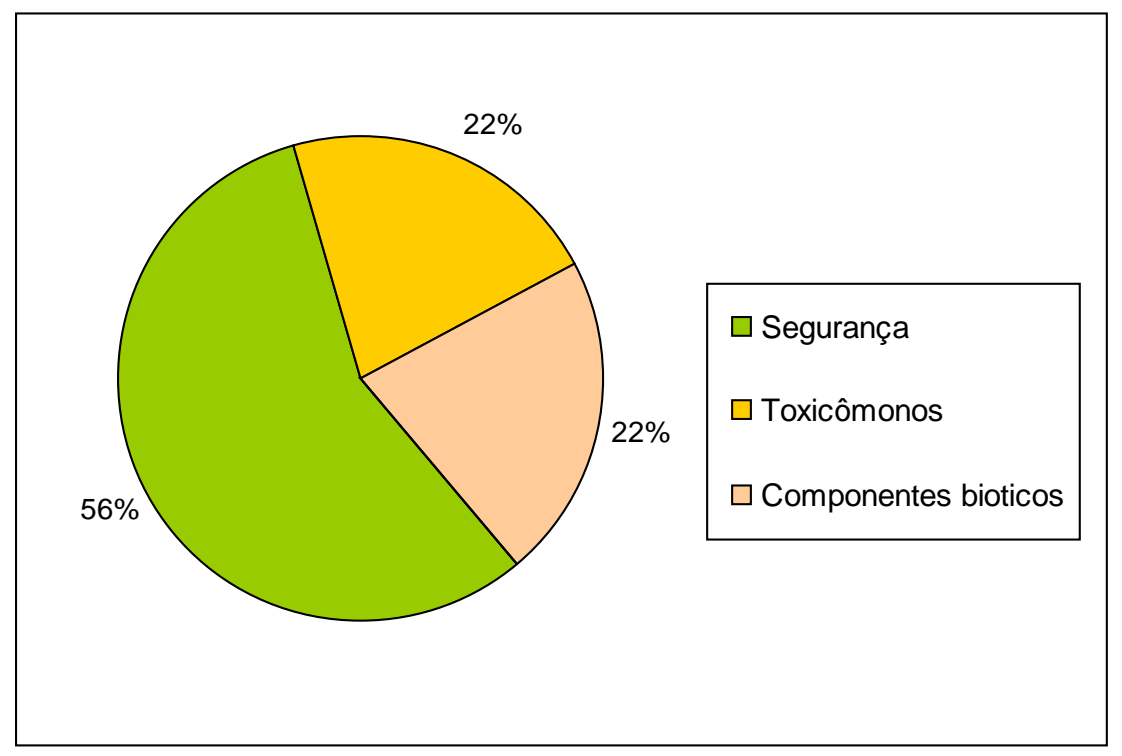


A presença de usuários de drogas no Mandhuy é fato, tem sido uma das maiores reclamações por parte da população de entorno do Mandhuy. Desse modo, essa questão precisa ser avaliada pelo poder público e também pela sociedade, pois essa problemática tem contribuído para tornar o Mandhuy em um espaço de incômodo, medo e restrição, mesmo observando os elevados índices de aceitação para com a área, confirmado na Questão n ${ }^{\circ}$ 2, quando os moradores apontaram inúmeras razões para morar perto do mesmo.

A problemática resultante do uso e dependência de drogas, especialmente entre jovens, vem alterando a relação de muitas comunidades que residem próximas a áreas naturais preservadas, principalmente quando estas estão localizadas em espaços urbanos, o que requer políticas públicas urgentes que possam alterar determinadas condutas sociais sem, no entanto, ferir o direito individual de acessar os espaços públicos. Outra questão que contribui para sensação de insegurança apresentada pelos moradores do entorno e também apontada pelos usuários, é a proximidade da delegacia de polícia ao Mandhuy. Muitos afirmaram categoricamente que já avistaram fugitivos da Delegacia sendo perseguidos por policiais no interior do Parque por diversas vezes. Além de relatarem que alguns já foram vitimas de assaltos e arrombamentos em suas residências e que os "meliantes" fugiram utilizando-se do Mandhuy. Moradoras afirmaram que alguns animais, como cobras, gambás, quatis e tatus se aproximam das suas residências contribuindo para sua insegurança.

Independente dos relatos acima descritos, na área do Mandhuy, não há fauna significativa, mas, nos módulos Fantasminha, Perobas e Uruçora, os moradores do entorno têm sérios problemas com os macacos-prego (Cebus apella), que são atraídos para as residências em busca de alimentos, muitas vezes estimulados pelos próprios moradores. No Mandhuy essa situação está se repetindo com a atração dos quatis (Nasua nasua), que em bandos aproximam-se das residências e alguns ao atravessarem as ruas de entorno do parque são atropelados ou atacadas por cães.
A relação entre comunidade de entorno e área natural protegida, precisa ser trabalhada, pois um dos objetivos dos Parques é preservar sua fauna e flora. Identificar as razões da movimentação desses animais em direção às residências pode ser um dos primeiros passos, além de procurar envolver os moradores do entorno como aliados nessa empreitada que é a preservação desse espaço. Os gestores da área podem orientar a comunidade para solucionar os principais problemas, evitando-se com isso a insatisfação dos moradores para com o Mandhuy e, também, evitar maiores gastos públicos para administrar esses espaços. Mesmo parte dos entrevistados afirmarem sentirem medo da proximidade do Módulo Mandhuy, 83\% (Tabela 4) asseguram que não se mudariam do seu entorno para outra rua ou bairro mais distante.

Os moradores expressam sua satisfação com o Módulo Mandhuy afirmando gostar da proximidade do Parque. Diante desses dados, conclui-se que os problemas que os incomoda, apontados na Questão $\mathrm{n}^{\circ}$ 3, ainda não constituem razões suficientes para forçar a saída de moradores do entorno, para outros locais distantes do Parque. Muito embora, em Cianorte não haja bairros muito distantes de alguns dos fragmentos vegetais que formam o Parque Cinturão Verde, assim residir longe dessa quase floresta urbana só se mudando de Cianorte. As respostas dadas à questão acima evidenciam que os moradores de entorno gostam de residir junto ao Mandhuy, embora tenham apontado elementos que podem perfeitamente ser melhorados e assim manter essa área como expressa um dos entrevistados.

Os $23 \%$ dos moradores entrevistados que disseram que se mudariam do entorno do Módulo Mandhuy apontaram a segurança como a causa principal para justificar possível mudança das proximidades dessa área. No entanto, se retomarmos as respostas dadas à Questão $n^{\circ} 2$, percebe-se que $95 \%$ dos entrevistados afirmaram gostar de morar perto do Módulo Mandhuy. Dessa forma, compreende-se que se esses moradores (23\%) tiverem oportunidade de se descolar definitivamente para outros locais da cidade mais distantes do Mandhuy, assim o farão, em função da insegurança associada à área. Os principais motivos que agradam aos moradores em 
permanecer residindo nas proximidades do Mandhuy relaciona-se ao próprio lugar, ao Mandhuy e alguns justificam a sua permanência no entorno dessa área por serem proprietários dos domicílios. (Figura 5)

Tabela 4. Opinião dos moradores do entorno do Módulo Mandhuy em permanecer residindo ou não nos bairros de seu entorno

Table 4. Opinion of the surrounding residents from module Mandhuy to remaining or not residing in the neighborhoods of its surroundin

\begin{tabular}{lc|cc|c}
\hline \hline Bairro & \multicolumn{3}{c}{ Sim } & \multicolumn{2}{c}{ Não } \\
\cline { 2 - 5 } & $\mathrm{N}^{\mathrm{o}}$ absoluto & $\%$ & $\mathrm{~N}^{\mathrm{o}}$ absoluto & $\mathbf{7 9}$ \\
\hline Zona 03 & 9 & 21 & 34 & 86 \\
Zona 07 & 1 & 14 & 6 & 70 \\
Conj. M. Marselha & 6 & 30 & 14 & $\mathbf{7 7}$ \\
\hline Total & $\mathbf{1 6}$ & $\mathbf{2 3}$ & $\mathbf{5 4}$ & \\
\hline \hline
\end{tabular}

Figura 5. Razões para o entrevistado não se mudar das áreas próximas ao Módulo Mandhuy

Figure 5. Reasons for the interviewed ones do not have moved from the Mandhuy Module neighborhood

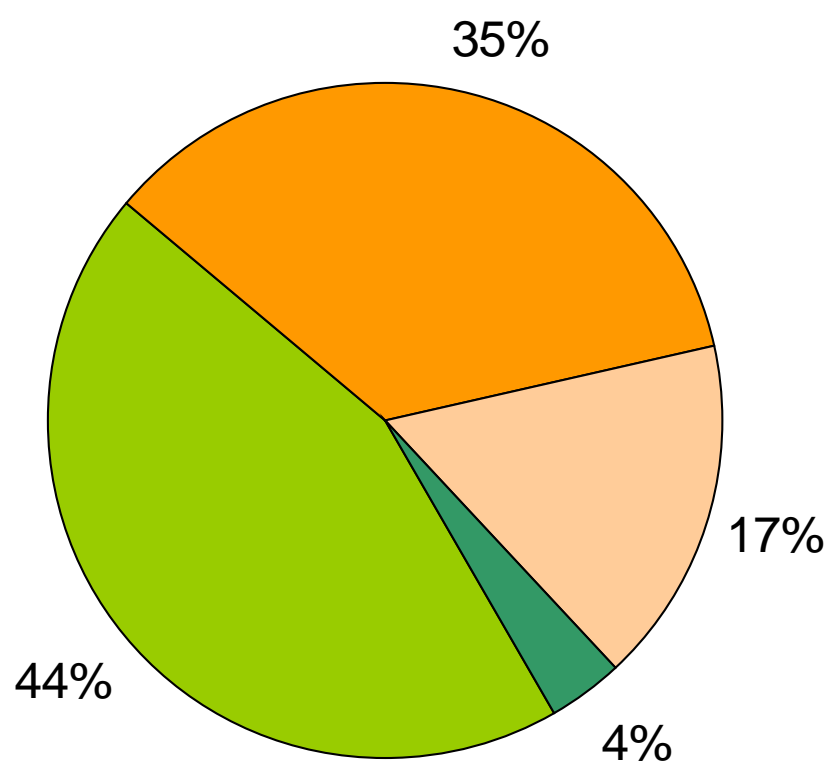

$\square$ Lugar

$\square$ Parque (natureza)

$\square$ Não Justificou

$\square$ Domicílio (proprietário)

A introdução da Questão $\mathrm{n}^{\circ}$ 5, teve como objetivo identificar se os moradores de entorno do Mandhuy sabem qual ou quais são as finalidades da existência dessa área, da mesma forma que investigamos o nível de entendimento dos usuários sobre essa temática. De acordo com os dados (Tabela 5), 61\% dos entrevistados afirmaram que sabem para que serve a área do Mandhuy. Entretanto, apontaram que o Mandhuy serve para, primeiro: atender suas necessidades, humanas e depois a preservação da natureza. 
Tabela 5. Opinião dos moradores do entorno do Módulo Mandhuy quanto a sua finalidade

Table 5. Opinion of the surrounding residents from Mandhuy Module as far as its purpose

\begin{tabular}{lc|c|c|c}
\hline \hline Bairro & \multicolumn{2}{c}{ Sim } & \multicolumn{2}{c}{ Não } \\
\cline { 2 - 5 } & $\mathrm{N}^{\mathrm{o}}$ absoluto & $\%$ & $\mathrm{~N}^{\mathbf{0}}$ absoluto & \% \\
\hline Zona 03 & 28 & 65 & 15 & 29 \\
Zona 07 & 5 & 71 & 2 & 50 \\
Conj. M. Marselha & 10 & 50 & 10 & $\mathbf{3 9}$ \\
\hline Total & $\mathbf{4 3}$ & $\mathbf{6 1}$ & $\mathbf{2 7}$ & \\
\hline \hline
\end{tabular}

As opiniões dos moradores sobre a finalidade da área do Módulo Mandhuy, não diferem muito. Assim temos quase o mesmo número de moradores que entendem que o Módulo Mandhuy tem funções, ora relacionadas à preservação, ora relacionadas a benefícios da população.

(Figura 6)

Figura 6. Finalidade do Módulo Mandhuy de com os moradores do seu entorno

Figure 6. The purpose of Mandhuy Module with the surrounding residents

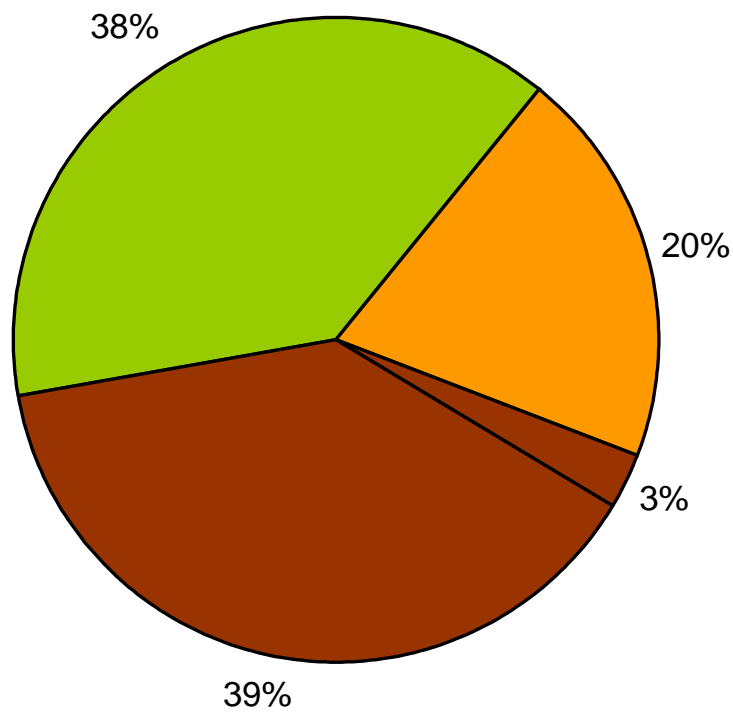

口Preservar a natureza

口Beneficiar a população

Preservar a natureza e uso da população

口Não sabe

Dos entrevistados, 38\% apontaram a preservação da natureza, visão ecológica, como a causa primeira da existência do Mandhuy. Com isso, o elemento humano é obrigatoriamente separado da mesma. Para uma Unidade de Conservação em espaço urbano, o elemento humano não deve ser apartado dos elementos naturais, sob pena do primeiro, em razão da sua natureza, de produzir cultura, degradar irreversivelmente o segundo.

No entorno do Módulo Mandhuy há alguns equipamentos de lazer, como um playground (Figura 7), e isto na visão de parte dos moradores caracteriza-se na função dessa área que é a de beneficiar a população. 
Figura 7. Infraestrutura de lazer no entorno do Módulo Mandhuy

Figure 7. Infraestrutura leisure in the surroundings Module Mandhuy

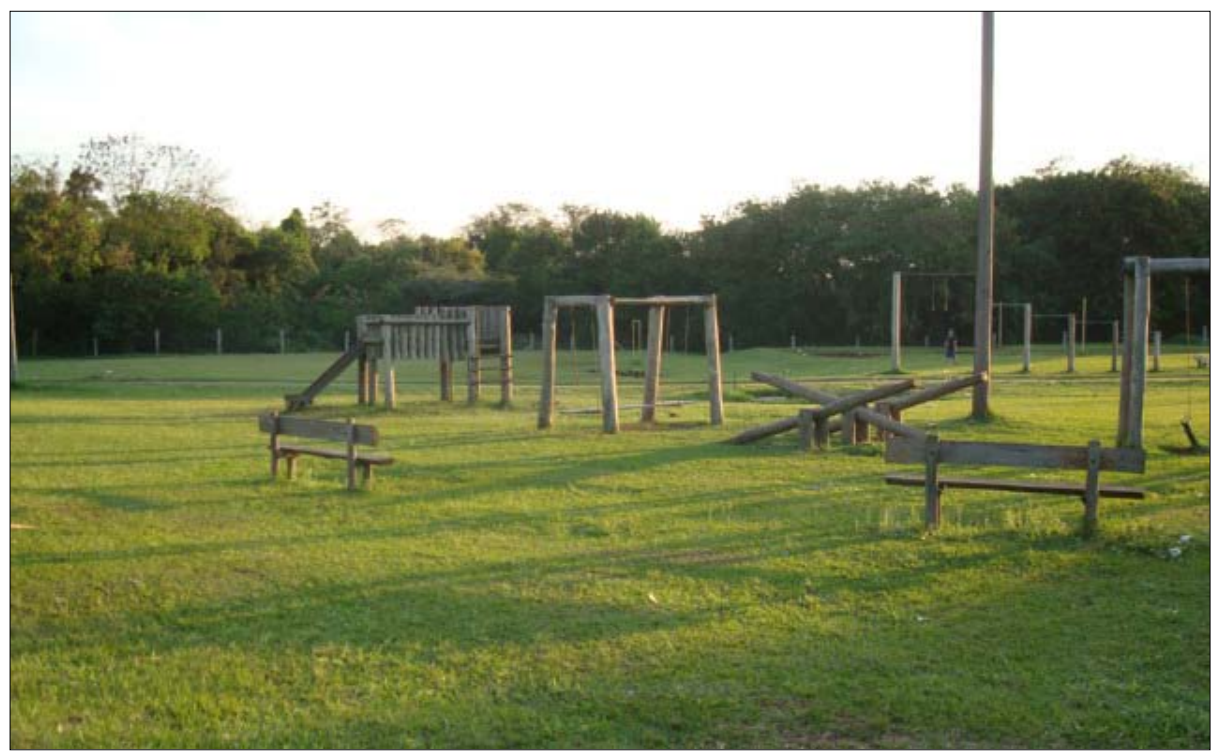

As Unidades de Conservação são criadas a partir de decisões políticas, mas sua criação deve ser precedida de informações adequadas e inteligíveis à população local e outras partes interessadas. Assim, informar a comunidade sobre a finalidade de uma Unidade de Conservação é decisivo para o sucesso dos objetivos para que foi criada. (BRASIL, 2000).

Pelo significativo número (39\%) de entrevistados (Tabela 6) que responderam não saber para que serve o Mandhuy, indica que a exigência acima não foi completamente cumprida.

No caso em estudo, nenhum dos moradores entrevistados soube responder a correta finalidade dessa área protegida, seus objetivos, suas limitações, o que podem ou não fazer em relação à área, sabem sim que é um parque. Entretanto, esperam que os órgãos públicos façam melhorias no mesmo, transformando-o em um parque completamente diferente do que se apresenta, um parque não para preservação, mas um parque de recreação.

PEIXOTO et al (2005, p.28) defendem a necessidade de se manter informada

[...] a população do entorno, com relação à unidade de conservação, suas importâncias artísticas, históricas $e$ ambientais e as formas de utilização deste espaço, a começar pelo seu conhecimento e a criação no imaginário dos cidadãos de um símbolo de natureza próximo que pode se harmonizar com a realidade de vida da cidade.

As áreas verdes urbanas, em muitos estudos, são apontadas como benéficas para as populações das cidades. Nesse contexto, inquiriu-se aos moradores de entorno se "Essa área lhe traz algum tipo de beneficio?”, $60 \%$ responderam que essa área lhes trás benefícios (Tabela 6). Assim, entendem que a presença do Módulo Mandhuy contribui para a melhoria da saúde, oferece paz, tranquilidade, ar puro, menos poluição, além de valorizar as suas propriedade e possibilitar uma vista privilegiada.

Nota-se, que há certa diversidade de benefícios apontados pelos moradores, sendo a qualidade ambiental uns dos itens mais citados, seguido pela sensação de bem estar, expressa quando associaram o Mandhuy à saúde física e mental para as populações do seu entorno imediato, além de oferecer espaço livre para atividades de lazer e contemplação. (Figura 8 e 9).

Muitos desses benefícios, apontados pelos moradores, são citados em estudos que abordam a importâncias das áreas verdes urbanas, quando estas são identificadas como elementos importantes para qualificar a vida das comunidades urbanas. Os estudos de Souza (2010) sobre as funções sociais e ambientais de parques urbanos em Curitiba, PR, ressalta que as atividades realizadas em áreas verdes urbanas são consideradas essenciais para reduzir o estresse e da pressão gerada pelo cotidiano da vida urbana.

Tabela 6. Opinião dos moradores do entorno do Módulo Mandhuy quanto aos seus benefícios 
Table 6. Opinion of the surrounding residents from Mandhuy Module as far as its benefits

\begin{tabular}{lc|cc|c}
\hline \hline Bairro & \multicolumn{2}{c}{ Sim } & \multicolumn{2}{c}{ Não } \\
\cline { 2 - 5 } & $\mathrm{N}^{\mathrm{o}}$ absoluto & $\%$ & $\mathrm{~N}^{\mathbf{0}}$ absoluto & 37 \\
\hline Zona 03 & 27 & 63 & 16 & 29 \\
Zona 07 & 5 & 71 & 2 & 10 \\
Conj. M. Marselha & 10 & 50 & 10 & $\mathbf{4 0}$ \\
\hline Total & $\mathbf{4 2}$ & $\mathbf{6 0}$ & $\mathbf{2 8}$ & \\
\hline \hline
\end{tabular}

Figura 8. Benefícios apontados pelos moradores do entorno do Módulo Mandhuy

Figure 8. Benefits pointed by the surrounding residents from Mandhuy Module

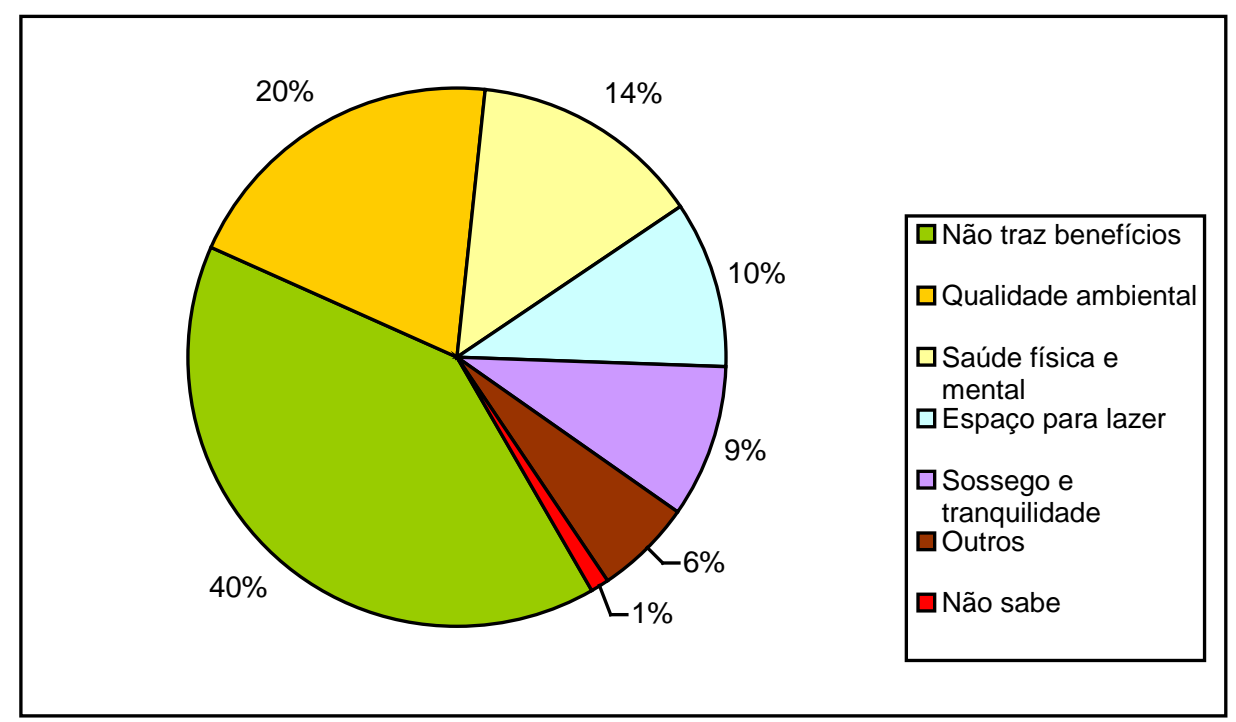

Figura 9. Pista de caminhada no entorno do Módulo Mandhuy

Figure 9. Walking track surrounding the module Mandhuy

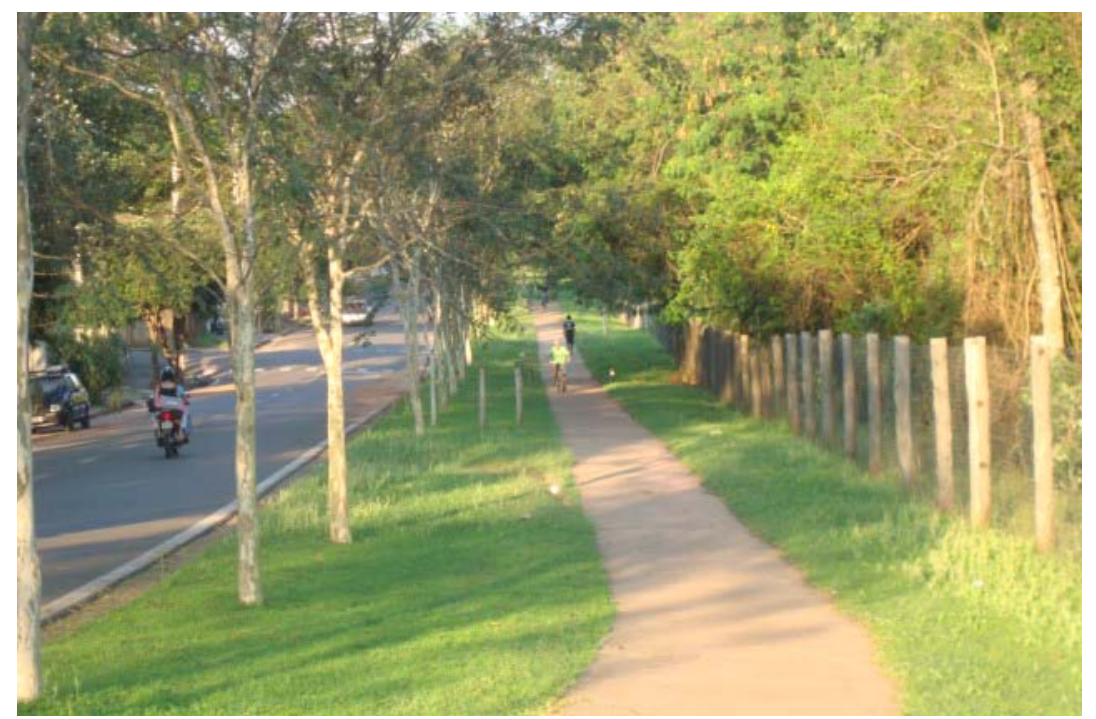


Os moradores que responderam que o Mandhuy não lhes traz nenhum beneficio (40\%) não apresentaram justificativa para sua resposta.

A presença de lixo na área (entorno e interior) é uma realidade impossível de esconder. Os usuários identificaram o lixo como um dos problemas mais importantes do Mandhuy. (Figura 10). Nesse contexto, questionou-se aos moradores se esses saberiam informar quem são os responsáveis pela deposição do lixo no Mandhuy.

Figura 10. Lixo disposto na área do Módulo Mandhuy

Figure 10. Provisions in the Waste Module Mandhuy

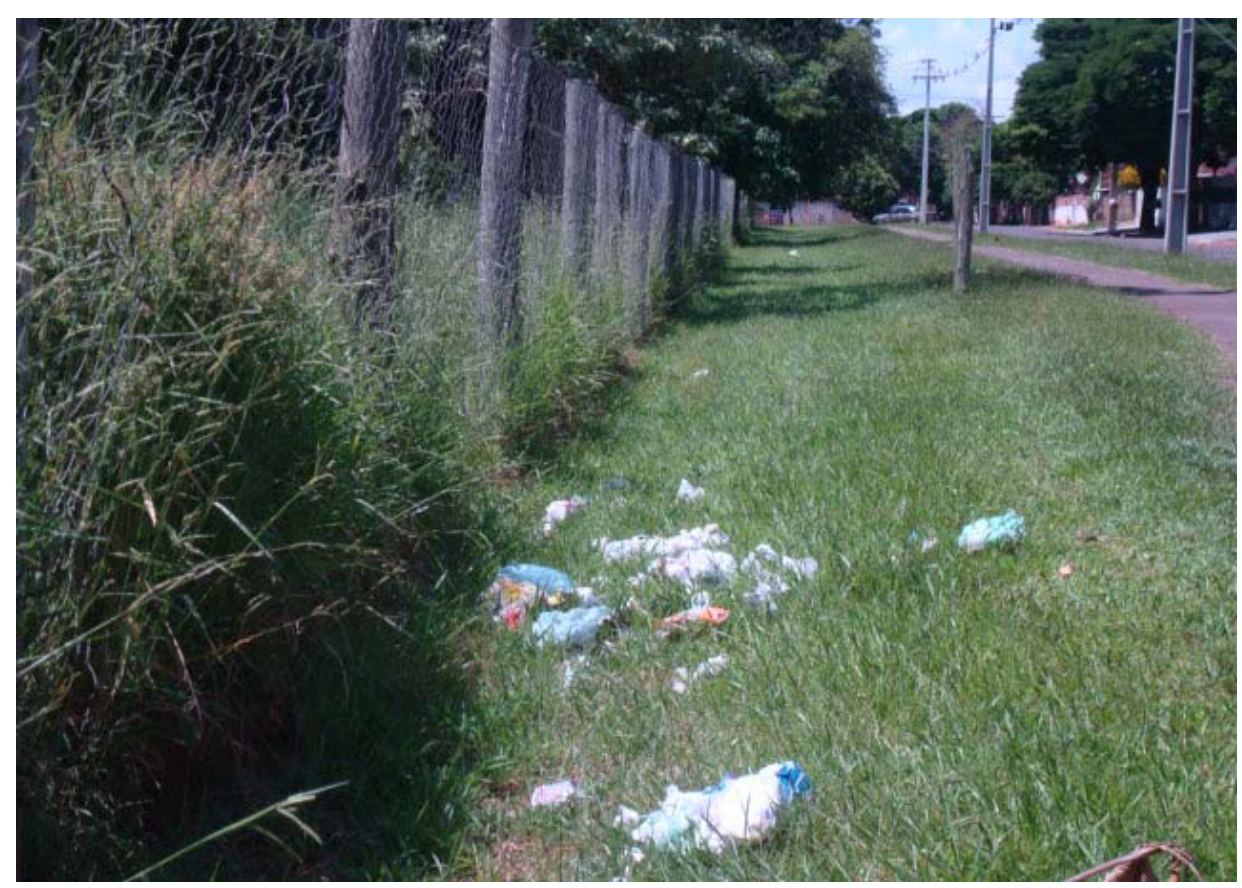

Dos moradores entrevistados, $\quad 59 \%$ (Tabela 7) respondeu não saber. Enquanto que 41\% afirmaram que os responsáveis pelo lixo são os vizinhos, os moradores de longe, os carroceiros (que levam entulhos para a Mãe Biela), os donos de empresas que recolhem entulhos. (Figura 11).

A questão do lixo no Mandhuy é reconhecida pelos moradores como de responsabilidade de toda comunidade, inclusive do Poder Público quando autorizou a deposição de resíduos, nas voçorocas que margeiam o Parque, a mais conhecida "Mãe Biela”, foi completamente soterrada com materiais dispostos pelo poder público e também pelos moradores. Outro importante ator responsável pela presença de lixo na área é a forma de coleta de resíduos realizada pela SANEPAR (Companhia de Saneamento do Paraná), que responde pela coleta em Cianorte.

Tabela 7. Se o morador do entorno saberia informar quem são os responsáveis pela disposição de lixo no Módulo Mandhuy Table 7. If the surrounding resident would know how to inform who the responsibles for waste the disposal in Mandhuy Module are

\begin{tabular}{lc|c|c|c}
\hline \hline Bairro & \multicolumn{2}{c|}{ Sim } & \multicolumn{2}{c}{ Não } \\
\cline { 2 - 5 } & $\mathrm{N}^{\mathrm{o}}$ absoluto & $\%$ & $\mathrm{~N}^{\text {o }}$ absoluto & $\%$ \\
\hline Zona 03 & 19 & 44 & 24 & 56 \\
Zona 07 & 5 & 71 & 2 & 29 \\
Conj. M. Marselha & 5 & 25 & 15 & 75 \\
\hline Total & $\mathbf{2 9}$ & $\mathbf{4 1}$ & $\mathbf{4 1}$ & $\mathbf{5 9}$ \\
\hline \hline
\end{tabular}


Figura 11. Responsabilidade pela deposição de lixo no Módulo Mandhuy

Figure 11. Responsibility for waste the disposal in Mandhuy Module

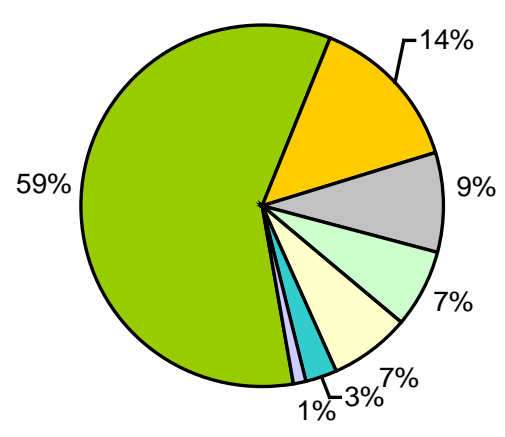

\begin{tabular}{|l|}
\hline Não Sabe \\
$\square$ Moradores mais \\
distantes \\
$\square$ Vizinhos \\
$\square$ População em geral \\
$\square$ Outros \\
$\square$ Usuários \\
$\square$ Empresas de \\
entulhos
\end{tabular}

Assim, procurou-se saber se o morador do entorno desenvolve alguma ação que contribui para com a manutenção do Mandhuy, como área preservada. Dos entrevistados $71 \%$ responderam que desenvolvem algumas ações de cuidados com o Módulo Mandhuy (Tabela 8).

Tabela 8. Se os moradores do seu entorno direcionam algum tipo de cuidado com o Módulo Mandhuy Table 8. If the surrounding residents guide any type of care with the Mandhuy Module

\begin{tabular}{lc|c|c|c}
\hline \hline Bairro & \multicolumn{2}{c}{ Sim } & \multicolumn{2}{c}{ Não } \\
\cline { 2 - 5 } & $\mathrm{N}^{\circ}$ absoluto & $\%$ & $\mathrm{~N}^{\circ}$ absoluto & $\%$ \\
\hline Zona 03 & 33 & 77 & 10 & 23 \\
Zona 07 & 6 & 86 & 1 & 14 \\
Conj. M. Marselha & 11 & 55 & 9 & 45 \\
\hline Total & $\mathbf{5 0}$ & $\mathbf{7 1}$ & $\mathbf{2 0}$ & $\mathbf{2 9}$ \\
\hline \hline
\end{tabular}

Fonte: Pesquisa realizada pela autora no Módulo Mandhuy, Cianorte 2010. Source: Survey carried out by the author in Mandhuy Module, Cianorte 2010.

Desse modo, perguntou-se aos que responderam que para isso? Assim afirmaram que ajudam cuidar do ajudam cuidar do Mandhuy (74\%), como e o quê fazem Mandhuy da seguinte maneira. (Figura 12)

Figura 12. Cuidados que os moradores direcionam ao Módulo Mandhuy

Figure 12. The care that the residents guide to the Mandhuy Module

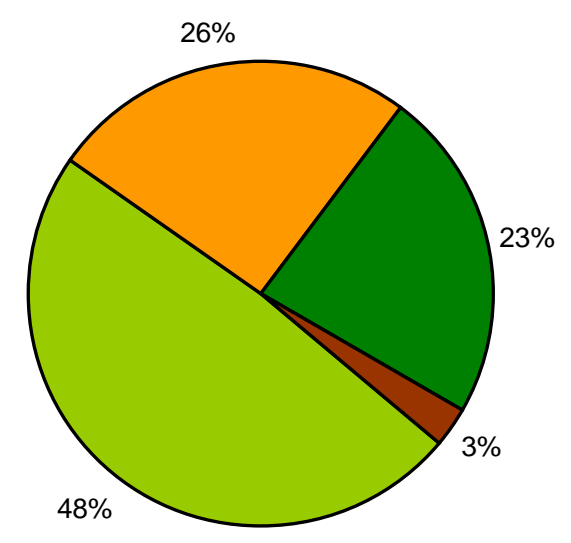

$\square$ Cuidados com lixo 口Não faz nada

पVigilância

口Outras ações
A maioria dos moradores entrevistados, se mostrou comprometida em também cuidar do Mandhuy. É relevante recorrer às analises de Yázigi (2002, p. 24) que afirma, que: “Quando amamos um lugar temos de lutar a todo custo para que não se degrade e nos faça crescer com ele”. 
Não foi possível nesse estudo listar todas as manifestações de cidadania, contrárias à presença de lixo no Mandhuy. Entendemos que o gestor não deva deixar de consultar a comunidade para discutir problemas relacionados a esta área, que tem como finalidade a conservação e a preservação dos componentes naturais ali existentes. Com isso, estará encorajando-os a participar plenamente da gestão dessa Unidade de Conservação, além de demonstrar que esses sujeitos são corresponsáveis pelos espaços públicos.

\section{CONCLUSÃO}

Desde a formação de Cianorte na década de 1950, a área do Módulo Mandhuy tem sido alterada pela ação da sociedade imprimida à paisagem. Mesmo levando em conta que essa área foi destinada á preservação desde o inicio da construção do espaço urbano cianortense, a sua gestão executada pelos órgãos responsáveis tem encontrado muitas dificuldades em manter sua integridade, evidenciando os parcos cuidados a ela destinados.

A criação de áreas naturais protegidas, na forma de parques, onde se procura, ao mesmo tempo preservar importantes representantes da fauna e flora e a sua utilização pelas comunidades diretamente envolvidas, de acordo com as normativas definidas nos planos de manejo, parece não representar isoladamente uma solução satisfatória para construir uma relação harmoniosa entre sociedade e natureza.

Nessa perspectiva, a separação da comunidade do entorno do Mandhuy, via cercamento, com o intuito de proteger esse retalho de natureza encravado no espaço urbano, tem contribuído para o agravamento dos impactos ambientais na área.

A separação entre Mandhuy e moradores do seu entorno também vem contribuindo para as interpretações negativas, (o parque como local de perigos, crimes, bandidagem, entorpecentes) e a identificação da área como paisagem de incômodo e medo.

As respostas dadas pelos moradores do entorno sugerem mudanças urgentes principalmente no modelo de gestão da Unidade de Conservação. Isso porque as limitações de uso imprimidas à área têm resultado em conflitos de interesse por parte desses atores sociais que almejam espaços para a prática de lazer livres de restrições que sequer compreendem.
Espera-se que a implementação do Plano de Manejo, elaborado em 2008, parte desses conflitos de interesse em relação aos possíveis usos, possam ser amenizados, mediante ação ampla e permanente de informação e conscientização dos sujeitos envolvidos.

Apesar da relação conflitante entre os interesses dos moradores do entorno com o Módulo Mandhuy, é importante ressaltar a valorização da área pelos entrevistados, vista como espaço verde em meio às construções da cidade, comparando-a a uma parte do paraíso, remetendo-o a elemento indispensável à qualificação da vida das comunidades vizinhas e de toda a cidade, patrimônio de todos. Aspectos como melhorias da condição climática da cidade, sensações de paz e tranquilidade gerado nos moradores vizinhos que percebem menos barulho, comuns em espaços urbanos, também foram citados. Em outros discursos, o Mandhuy é considerado espaço de lazer, possibilitando o contato com a natureza. Além desses benefícios, outros foram destacados pelos entrevistados como a saúde física e mental.

Dessa forma, os resultados dessa pesquisa contribuirão diretamente com benefícios sociais e ambientais para o sistema Mandhuy - Comunidade, e que as intervenções por parte dos gestores e administradores públicos resultem em ações benéficas quanto a sustentabilidade a curtos e médios prazos, tanto para os elementos do meio como para a qualidade de vida das comunidades do entorno imediato dessa área. 


\section{REFERÊNCIAS}

BALlarotTI, L. Análise das Condições ambientais do Parque Arthur Thomas e sua importância para a população de Londrina - PR. Dissertação (Mestrado em Geociência). Universidade Estadual de Londrina, Londrina. 2005

BIONDE, D.; MÓRMUL, M. L. Parques Urbanos de Curitiba/PR - qual a Preferência de seus usuários?. In: Anais...VII Encontro Nacional de Paisagismo em Escolas de Arquitetura e Urbanismo no Brasil. Belo Horizonte. 2004. Disponível em: $<$ http://www.usp.br/fau/>. Acesso em 04 ago. 2009.

BRASIL. Ministério do Meio Ambiente. Sistema Nacional de Unidades de Conservação da Natureza. SNUC - Lei $\mathbf{n}^{\circ}$ 9.985, de 18 de julho de 2000. Brasília: MMA, 2000.

CIANORTE Lei Municipal no 1.534. Criou o Parque Municipal do Cinturão Verde - Módulo Mandhuy. Cianorte, 1993.

FERREIRA, A. Efeitos Positivos gerados pelos parques urbanos - O caso do Passeio Público do Rio de Janeiro.Dissertação (Mestrado em Ciência Ambiental) Universidade Federal Fluminense, Rio de Janeiro, 2005.

GONÇAVES, C. W. P. Os (des)caminhos de meio ambiente. 13ª ed. São Paulo: Contexto, 2005.

IAP - Instituto Ambiental do Paraná. Curitiba, 2000.

INSTITUTO BRASILEIRO DE GEOGRAFIA E ESTATÍSTICA. Censo demográfico - 2000. Brasília: IBGE 2000.

MAZZEI, K; COLESANTI, M. T. M., SANTOS, D. G. Áreas Verdes Urbanas, Espaços Livres para o Lazer. Revista Sociedade \& Natureza. Uberlândia, 19 (1): p. 33 - 43, jun. 2007. <http://www.sociedadenatureza.ig.ufu.br/>. Acesso 23 set. 2009.

MENDONÇA, F. Geografia Socioambiental. (p. 121-144). In: MENDONÇA, F. e KOZEL, S. (orgs). Elementos de Epistemologia da Geografia Contemporânea. Curitiba, Ed. da UFPR, 2004.

PAZ, R. J; FREITAS, G. L.; SOUZA, E. A. Unidades de conservação no Brasil: História e legislação. João Pessoa. Ed. Universitária: UFPB, 2006.

PAIVA, H. N.; GONÇALVES, W.r. Florestas Urbanas: planejamento para melhorias da qualidade de vida. Viçosa. Aprenda Fácil, 2002.

PEIXOTO et al. Parque Urbano da Paz: a construção de um novo conceito no parque Nacional da Tijuca. RDE REVISTA DE DESENVOLVIMENTO ECONÔMICO - Ano VII . No 11. janeiro de 2005. Salvador, BA - P. 24 a 29.

SERAPHUM, D. S. Unidades de conservação em áreas de preservação permanente urbanas: implementação e percepção na cidade Curitiba, PR, BRASIL. Dissertação (Mestrado Profissional em Gestão Ambiental). Universidade Positivo, Curitiba. 2010.

SOUZA, P.C.A. Funções sociais e ambientais de parques urbanos instituídos como unidade de conservação: percepção dos usuários do Parque Natural Municipal Barigui em Curitiba, Paraná. Dissertação. (Mestrado em Gestão Urbana). Universidade Católica do Paraná, Curitiba, 2010.

SOUZA, B. I.; SUERTEGARAY, D. M.A. Considerações sobre a Geografia e o Ambiente. Revista OKARA: Geografia em debate. V.1, n.1, p. 5-15, 2007. Disponível em: <http://www.okara.ufpb.br/>. Acesso 26 ago. 2008.

YÁZIGI, E. A alma do Lugar: Turismo, planejamento e cotidiano. São Paulo: Contexto, 2002.

YIN, R. K. Estudo de Caso: Planejamento e Métodos. Porto Alegre: Bookman, 2001. 